Article

\title{
Hybrid Metaheuristic-Based Spatial Modeling and Analysis of Logistics Distribution Center
}

\author{
Maryam Khairunissa and Hyunsoo Lee *(D) \\ School of Industrial Engineering, Kumoh National Institute of Technology, Gumi 39177, Korea; \\ mary@kumoh.ac.kr \\ * Correspondence: hsl@kumoh.ac.kr
}

Citation: Khairunissa, M.; Lee, H. Hybrid Metaheuristic-Based Spatial Modeling and Analysis of Logistics Distribution Center. ISPRS Int. J. Geo-Inf. 2022, 11, 5. https://doi.org/ $10.3390 /$ ijgi11010005

Academic Editor: Wolfgang Kainz

Received: 18 September 2021

Accepted: 26 December 2021

Published: 28 December 2021

Publisher's Note: MDPI stays neutral with regard to jurisdictional claims in published maps and institutional affiliations.

Copyright: (C) 2021 by the authors. Licensee MDPI, Basel, Switzerland. This article is an open access article distributed under the terms and conditions of the Creative Commons Attribution (CC BY) license (https:// creativecommons.org/licenses/by/ $4.0 /)$.

\begin{abstract}
The location analysis of logistics distribution centers is one of the most critical issues in large-scale supply chains. While a number of algorithms and applications have been provided for this end, comparatively fewer investigations have been made into the integration of geographical information. This study proposes logistic distribution center location analysis that considers current geographic and embedded information gathered from a geographic information system (GIS). After reviewing the GIS, the decision variables and parameters are estimated using spatial analysis. These variables and parameters are utilized during mathematical problem-based analysis stage. While a number of existing algorithms have been proposed, this study applies a hybrid metaheuristic algorithm integrating particle swarm optimization (PSO) and genetic algorithm (GA). Using the proposed method, a more realistic mathematical model is established and solved for accurate analysis of logistics performance. To demonstrate the effectiveness of the proposed method, Korea Post distribution centers were considered in South Korea. Through tests with several real-world scenarios, it is proven experimentally that the proposed solution is more effective than existing PSO variations.
\end{abstract}

Keywords: logistics centers location; spatial analysis; geographic information system; hybrid metaheuristics; particle swarm optimization; genetic algorithm

\section{Introduction}

The efficiency of logistics networks and systems in decreasing travel time and reaching longer-distance markets is considered important for enhanced economic growth [1]. By acknowledging the importance of logistics activities, the World Bank helps countries measure their improvement by providing a logistics performance index (LPI). The updated LPI methodology [2] features micro-level performance data and geospatial data in their qualitative assessments, demonstrating that geospatial data plays an important role in measuring logistics performance.

Most countries consider their transportation infrastructure and logistics centers as business generators [3]. The location decision of logistics centers and their performances are crucial, as they help companies not only minimize costs, traffic congestion, and environmental pollution levels, but also improve the scheduling system and vehicle routing [4-7]. This is especially the case with environmental concerns since it is not only the responsibility of logistics companies but also an issue for government and other stakeholders, as well as one of customers awareness [8].

Furthermore, Europlatforms [9] has explained that logistics centers not only operate a commercial basis to benefit transport, logistics and distribution but also offer key logistical functions, such as coordination, centralization, consolidation, collaboration, and integration in a specific area's hub. Then, in the process of formulating these logistical functions, the system will be not only working for the logistics companies but also has the ability to minimize or even overcome the general issues mentioned above [10]. Creating specific strategies and human research evaluation are also needed to see the system's overall efficiency [11,12]. 
While a number of research studies have been proposed for analyzing logistic facilities, efforts to incorporate real-world data, such as geographic information system (GIS) data including facility information, have more recently begun. The integration of GIS data and existing algorithms can help enhance the performance of logistics facilities. This study proposes a hybrid metaheuristic model based on spatial analysis for measuring distribution performance of logistic centers quantitatively. In particular, post-logistics in South Korea are examined in this research.

The methodology of this study mainly consists of two parts: (a) spatial and network analysis using GIS, and (b) mathematical model-based location analysis using hybrid PSOGA model. Hybrid of PSO-GA is effective in incorporating very large-scale instances and can be developed using various parameters.

To validate our research findings, we performed logistic center location analysis on the GIS data of Korea Post locations around the country, including population density and other information. South Korea has a total land area of $97,230 \mathrm{~km}^{2}$, with $81.8 \%$ of the 2020 population being urban and uneven population density $[9,13]$.

The remainder of this paper is organized as follows. Section 2 provides relevant background knowledge and a literature review. Section 3 proposes the model and methodology with a deeper theoretical background analysis. Finally, Section 4 presents the application, and results of the proposed methodology are provided in Section 4.

\section{Materials and Method}

\subsection{Background and Literature Reviews}

Rodrigue et al. [14] examined the standardization of logistics centers of various sizes based on terminal size and logistics facilities hierarchy. Moreover, selecting and evaluating the size and hierarchy of logistics centers has been one of the essential elements of business operations. Well-planned logistics center allocation helps reduce logistics costs and improve the efficiency of distribution flows [15].

Furthermore, delivery options and distribution flows are improved to welcome changes in shopping behavior, such as extending conventional home delivery to car boot delivery, in-home delivery, store collection, and more [16]. It is important to note that the ability to ship goods reliably at a low cost determines a country's participation strategy in global value chains [17].

In terms of logistics costs, there are five common components, as indicated by Pohit et al. [18]: transportation costs, warehousing costs for both in-house and outsource, administration costs, inventory-holding costs, and inventory-carrying costs. In addition to considering the aforementioned roles, logistics center locations should be suitable for integrated and other transportation modes. In fact, the fluidity of transport flows and profitability are closely interlinked by transport accessibility, market coverage, land availability, and other spatial factors.

Furthermore, in reaching the optimal decisions is needed in the least amount of time. The possibility in transitioning the predictive analytics and planning of just-in-time management to develop the dynamics physical distribution can be reached by implementing the mathematical model as well as artificial intelligence [19].

For this reason, a number of existing studies have mentioned the importance of building larger and more efficient facilities to meet regional and national demands [20]. The larger the size of the logistics network, the greater the complexity of its functions [21-23]. Thus, logistics centers should tackle this issue by adopting a spatial strategy to evaluate the optimal location for maximizing service coverage [24].

Identifying suitable logistics locations can be conducted in a number of ways. Quantitative analyses such as those performed by Hagino and Endo [25] have estimated the location of facilities and distribution centers using a multinomial logit model (MNL). Many metaheuristics, including adaptive PSO, have been applied to achieve the location of logistics centers as well [26]. 
High performance optimization of a large-scale logistic network is carried out using a modified discrete algorithm of PSO that handles binary decision variables (BPSO) [27]. Satisfactory results are also achieved considering the updated inertia weight, best-fit solutions, and worst-fit solutions from a hybrid PSO and genetic algorithm [28]. This study applied an integrated PSO-genetic algorithm approach for logistics network performance analysis. Table 1 shows the results of several existing studies on metaheuristic-based logistic centers.

Table 1. Metaheuristic-based decision of logistic networks.

\begin{tabular}{ccc}
\hline Research Studies & Applications & Applied Metaheuristics \\
\hline $\begin{array}{c}\text { Location Analysis [29] } \\
\text { (Cakmak et al.) }\end{array}$ & $\begin{array}{c}\text { Analyzing the location of logistics } \\
\text { centers }\end{array}$ & BPSO \\
\hline $\begin{array}{c}\text { Logistics Network [30] } \\
\text { (Yoshiaki Shimizu et al.) }\end{array}$ & Large-scale Logistics Network & BPSO \\
\hline $\begin{array}{c}\text { Routing Problem [31] } \\
\text { (A. Hiassat et al.) }\end{array}$ & $\begin{array}{c}\text { Location-Inventory Routing } \\
\text { Problem with Perishable Products }\end{array}$ & GA \\
\hline $\begin{array}{c}\text { Vehicle Routing [32] } \\
\text { (Y. Gajpal et al.) }\end{array}$ & $\begin{array}{c}\text { Vehicle Routing Problem with } \\
\text { simultaneous delivery and pickup }\end{array}$ & Ant Colony System (ACS) \\
\hline $\begin{array}{c}\text { Supply Chain Network [33] } \\
\text { (A. Shoja et al.) }\end{array}$ & $\begin{array}{c}\text { Supply Chain Network Design } \\
\text { with Direct Shipment }\end{array}$ & GA, PSO \\
\hline $\begin{array}{c}\text { Vehicle Routing [34] } \\
\text { (V. Kachitvichyanukul et al.) }\end{array}$ & $\begin{array}{c}\text { Multi-depot Vehicle Routing with } \\
\text { multiple Delivery and Pickup }\end{array}$ & PSO \\
\hline $\begin{array}{c}\text { Vehicle Routing [35] } \\
\text { (M. Marinaki et al.) }\end{array}$ & $\begin{array}{c}\text { Vehicle Routing Problem with } \\
\text { Stochastic Demands }\end{array}$ & $\begin{array}{c}\text { Glowworm Swarm } \\
\text { Optimization (GSO) }\end{array}$ \\
\hline $\begin{array}{l}\text { Vehicle Routing [36] } \\
\text { (M. Albayrak et al.) }\end{array}$ & \begin{tabular}{c} 
Traveling Salesman Problem \\
\hline
\end{tabular} & GA \\
\hline
\end{tabular}

Alternatively, spatial density analysis highlights trip distance minimization as a major factor in choosing the location of facilities in the real world [37]. Similar analyses have been noticed in that the logistics activities concentration or spatial clusters are counted while having logistics relocation [38]. GISs handle all the necessary physical and environmental constraints and have a significant role as a decision support tool for optimizing locations [39]. The implementation of GIS also improves service quality and employee performance by providing optimum routes [40]. Furthermore, GIS can compute distances in the network location model to obtain the shortest or fastest routes and solve logistics network problems. For instance, Klose and Drexl [41] proposed the location of logistics facilities using the criteria of minimizing the sum of distances between nodes and the nearest facility.

Respecting the complexity of logistics, we considered a well-formulated geographicalarea-and-mathematical-model combination for evaluating and selecting the appropriate location of logistics centers [42]. Optimal clustering of numerous logistics activities can be approached by employing GIS as a spatial analyzer and BPSO as a metaheuristic model [29]. Therefore, the aim of this study was to integrate GIS and metaheuristic algorithms that will manage large-scale, real-world logistics instances. In this research, a comprehensive integrated solution for the selection of logistics center locations is presented using real GIS data.

\subsection{Integration of GIS Data and PSO-GA Algorithm}

As mentioned previously, there are two stages used in this study to achieve an efficient solution for analyzing the logistics center location problem. While most of the research studies focused on quantitative analysis of distribution network using mathematical frameworks, the proposed method provides how GIS information is used for the quantitative 
analyses and their mathematical models. These incorporations and the detailed mechanism are the contributions of this study.

The proposed method is provided in Figure 1.

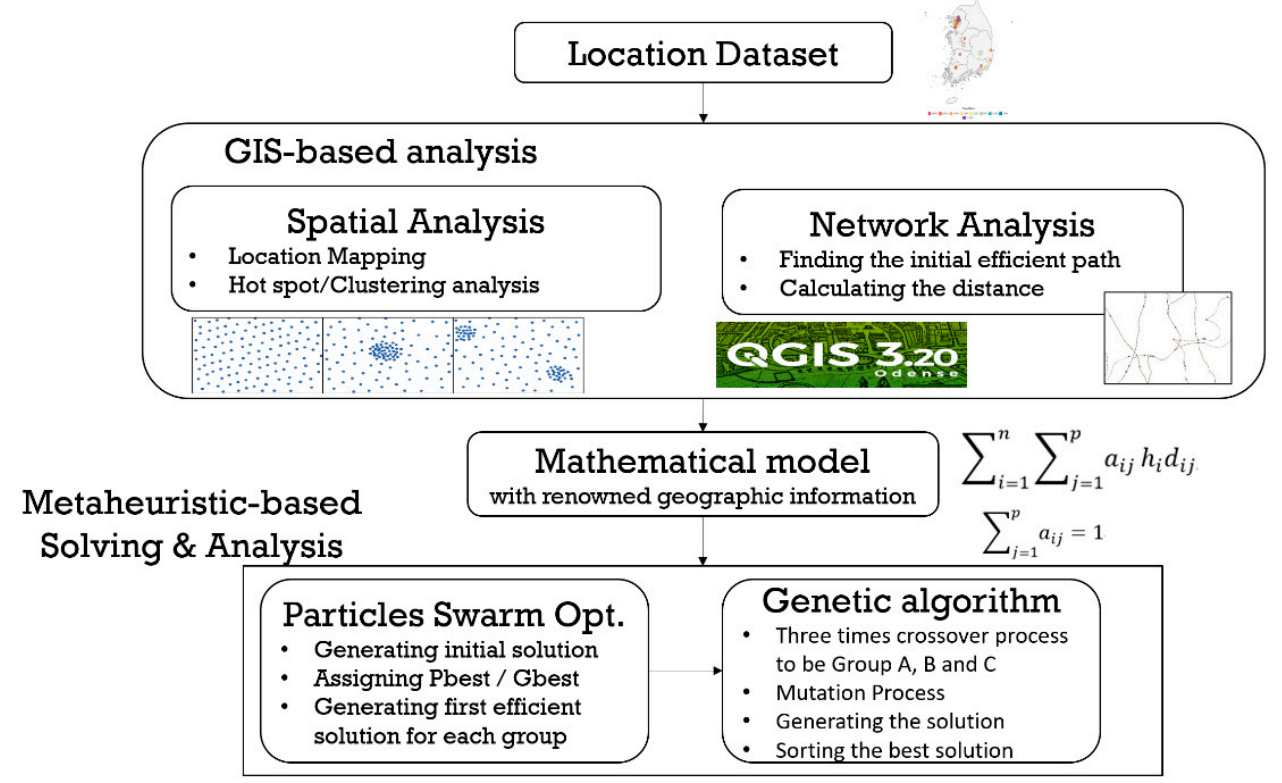

Figure 1. The schema for the proposed method.

The first step is a geographic analysis that involves spatial analysis and network analysis. Spatial analysis calculates the logistics densities by mapping the smaller Korea Post locations (demands) and showing the priority values of the demands. Network analysis provides the exact distances between demands. In this stage, the calculated densities and distances among the demands are considered when choosing the optimal route. The next step is to analyze the influence of the location utilizing the hybrid PSO-GA as the metaheuristic tool. There are several existing research studies that evaluate the logistics center's performance using PSO and GA separately. Table 1 shows the performances of methods using PSO and GA, and the standalone tests and combination tests using these metaheuristics are performed. As the result, the PSO-GA algorithm has better performances in this study.

\subsubsection{Spatial and Network Analysis Using GIS}

Geospatial analysis provides effective and value-based decision making and the best potential analysis using the capabilities of GIS in geospatial data management [43]. In general, the spatial network structure is constructed using the shortest paths among facilities as an adjacency matrix. Additionally, the characteristics of the network should be accounted for to build a hierarchical transportation system. Moreover, the logistics center is expressed by a candidate point (on the geographic data vector) and located on the vertex nodes of the road transportation system [44].

The prepared network will then be calculated to find its Origin-Destination (OD) distance (distance between any selected demands) with distance metrics to obtain the shortest paths or time metrics to obtain the fastest paths using Dijkstra's algorithm. In addition to finding the shortest and fastest paths, spatial analysis also applies powerful statistical tools to address dependence and heterogeneity through essential event frequencies at neighboring locations (hotspots identification) [45].

The statistical tools in GIS were assigned in the initial analysis to determine the autocorrelation using the global Moran's I calculation [46]. Moran's I uses the position, distance, and value of neighbor characteristics. The index value ranges from -1 to 1 , where -1 indicates dispersed activities, and 1 indicates clustered activities. If a value is approximately zero, it indicates a random pattern [46]. 
Mathematically, Moran's I statistic for spatial autocorrelation is given in Equation (1).

$$
\operatorname{Moran}^{\prime} s I=\frac{\left[n \sum_{i=1}^{n} \sum_{j=1}^{n} W_{i j}\left(X_{i}-\bar{X}\right)\left(X_{j}-\bar{X}\right)\right]}{\left[n \sum_{i=1}^{n} \sum_{j=1}^{n} W_{i j}\left(X_{i}-\bar{X}\right)^{2}\right]}
$$

where

$n=$ total number of features/spatial units;

$X_{i}=$ the index value at location $j$;

$\bar{X}=$ the global mean value;

and, $W_{i j}=$ the spatial weight among location " $i$ " and location " $j$ ".

To exhibit significant clustering or dispersion statistically, the $z$-score and $p$-value are required. As shown in Equation (2), z-score is the standard deviation of a feature from its mean and is based on randomization null hypothesis computation.

$$
z=\frac{I-E[I]}{\sqrt{V[I]}}
$$

Used in (2), $E[I]$ and $V[I]$ are defined in Equations (3) and (4), respectively.

$$
\begin{gathered}
E[I]=-\frac{1}{(n-1)} \\
V[I]=E\left[I^{2}\right]-E[I]^{2}
\end{gathered}
$$

When the $p$-value is very, the observed spatial pattern is the result of a random process, and the null hypothesis should be rejected. On the other hand, the higher (or lower) the $z$-score, the more intense the clustering. As with global Moran's I index value, a near-zero zscore indicates no apparent spatial clustering [39]. The decision to reject the null hypothesis is determined by the confidence level as shown in Table 2.

Table 2. The uncorrected critical z-scores and $p$-values for different confidence levels.

\begin{tabular}{ccc}
\hline$z$-Score (Standard Deviations) & $p$-Value (Probability) & Confidence Level \\
\hline$<-1.65$ or $>+1.65$ & $<0.10$ & $90 \%$ \\
$<-1.96$ or $>+1.96$ & $<0.05$ & $95 \%$ \\
$<-2.58$ or $>+2.58$ & $<0.01$ & $99 \%$ \\
\hline
\end{tabular}

Finally, hot spot values are calculated using Getis-Ord tools as shown in Equation (5) and used in the mathematical model as $h_{i}$ parameters.

$$
G i(d)=\frac{\sum_{j=1}^{n} w_{i j}(d) x_{j}}{\sum_{j=1}^{n} x_{j}}
$$

\subsubsection{Mathematical Model for Logistics Network Analysis}

Most location allocation problems involve selecting a certain number of logistics centers, and mapping to the demand or destination points within a maximized or minimized distance. One of the optimization problems allocates facilities (logistics centers) and assigns them to the demand or destination points. This optimization also minimizes the sum of the weighted distances between all destination points and related facilities [47]. The minimized weighted demand distance between the destinations and facilities is given by a set of destinations: $D=\left(d_{1}, d_{2}, \ldots, d_{n}\right)$. Each destination $\left(d_{i}\right)$ has coordinates and demands. The number of required facilities is labeled as $p$ and the $p$-facility locations $(x)$ out of the $n$-destinations are selected to map each destination to a facility. A binary parameter is applied to denote the destination $d_{i}$ mapped to facility $x_{j}$. For each destination, the 
binary parameter is expressed by $a_{i j}$ as shown in Equation (6) and followed by the objective function $\operatorname{cost}(x)$ in Equation (7). Table 3 provides the parameter descriptions.

$$
\begin{gathered}
\sum_{j=1}^{p} a_{i j}=1 \\
a_{i j}\left\{\begin{array}{c}
1, \text { if the destination } i \text { is assigned to facility at point } j \\
0, \text { otherwise }
\end{array}\right. \\
\text { Minimize } \operatorname{cost}(X)=\sum_{i=1}^{n} \sum_{j=1}^{p} a_{i j} h_{i} d_{i j},
\end{gathered}
$$

Table 3. Parameter descriptions.

\begin{tabular}{cc}
\hline Parameters & Description \\
\hline$d_{i j}$ & Distance between origin and destination \\
$h_{i}$ & Logistics density \\
$p$ & Number of logistics centers \\
$n$ & Number of destination nodes \\
$a_{i j}$ & Binary parameter for assigned case \\
\hline
\end{tabular}

As shown in Table 4, this mathematical model is solved using an integrated model, including PSO and GA. PSO is a stochastic optimization-based method that uses observed social behavior and initializes a random solution through a potential solution in the problem space.

Table 4. Mathematical Models.

\begin{tabular}{c} 
Mathematical Models \\
\hline$x_{i}=\left(x_{i 1}, x_{i 1}, \ldots, x_{i D}\right) \in S$ \\
$v_{i}=\left(v_{i 1}, v_{i 1}, \ldots, v_{i D}\right)$ \\
$p_{i}=\left(p_{i 1}, p_{i 1}, \ldots, p_{i D}\right) \in S$ \\
$x_{i}^{(t+1)}=x_{i}^{(t)}+v_{i}^{(t+1)}, i=1, \ldots, P$ \\
$x_{i}^{(t+1)}=x_{i}^{(t)}+v_{i}^{(t+1)}, i=1, \ldots, P$ \\
$v_{i}^{(t+1)}=v_{i}^{(t)}+c_{1} r_{i 1} \times\left(\right.$ pbest $\left._{i}^{(t)}-x_{i}^{(t)}\right)+c_{2} r_{i 2} \times\left(\right.$ gbest $\left._{i}^{(t)}-x_{i}^{(t)}\right)$
\end{tabular}

Presented as dimensional vectors (D), each particle is described in Equation (9) using the randomly generated initial velocity in Equation (10). Equation (11) defines the best local position of each particle, while Equations (12) and (13) are their adjusted personal positions and velocities according to the best solution for each particle (pbest) and the best solution of all populations (gbest) among particles in their neighborhood.

This study uses PSO because of it is simple, easy to implement, requires few parameters and has an important characteristic that GA does not have [48]. One drawback of PSO is premature convergence.

On the other hand, GA, developed by John Holland, uses recombination, mutation, and selection processes as its operators. GA has been applied to wide-range optimization problems and discrete and continuous systems. GA features enable the calculation of various type of optimizations because multiple offspring act independently in a population and explore the search space simultaneously in many directions [49]. Despite the advantages of GA, population size, new population and other selection parameters should be chosen wisely. Otherwise, it will be difficult to converge and may produce meaningless results.

To obtain an objective function that is superior to PSO and GA individually, we added the capability to present pbest and gbest. We expected the potential to achieve a more robust solution in a reasonable time and the detailed procedures are provided in Table 5. 
Table 5. The procedures of the proposed PSO-GA model.

\begin{tabular}{|c|c|}
\hline Procedures & Description \\
\hline Step 1. Initialization (for $\mathrm{k}=0$ ) & Set the starting value of pbest and gbest as zero. \\
\hline Step 2. For $i=1$ to $\mathrm{N}$ & Calculating the solution for the first iteration. \\
\hline $\begin{array}{l}\text { Step 3. Generate the initial } \\
\text { solution randomly }\end{array}$ & $\begin{array}{l}\text { Make an initial random population/particles as basic } \\
\text { starting solution to generate an initial population. }\end{array}$ \\
\hline Step 4. Calculate the initial solution & $\begin{array}{l}\text { By using the objective function, the fitness for all } \\
\text { solutions is calculated. The objective function will } \\
\text { maximize the profit. }\end{array}$ \\
\hline Step 5. Assign pbest & $\begin{array}{l}\text { Get the best solution for each particle/initial position } \\
\text { and update the pbest with the best solution (pbest'). }\end{array}$ \\
\hline Step 6. Assign gbest & $\begin{array}{l}\text { Get the best position among all particles and update } \\
\text { the gbest with the best solution (gbest'). }\end{array}$ \\
\hline Step 7. Generate initial velocities & Velocities are generated randomly. \\
\hline Step 8. Storing the solution & Store the best solution, best cost, and worst cost. \\
\hline $\begin{array}{l}\text { Step 9. Crossover process } 1 \\
(\text { for } \mathrm{k}=1: \mathrm{nc} / 2 \text { ) }\end{array}$ & $\begin{array}{l}\text { Children are generated from all current populations } \\
\text { (half of current populations)-Group A. }\end{array}$ \\
\hline Step 10. Generate the solution & The fitness for the Group A solution. \\
\hline Step 11. Crossover process 2 & $\begin{array}{l}\text { Children are generated from all current populations } \\
\text { with its pbest solution-Group B. }\end{array}$ \\
\hline Step 12. Generate the solution & The fitness for Group B solution. \\
\hline Step 13. Crossover process 3 & $\begin{array}{l}\text { Children are generated from all current populations } \\
\text { with its gbest solution-Group C. }\end{array}$ \\
\hline Step 14. Generate the solution & The fitness for Group C solution. \\
\hline $\begin{array}{l}\text { Step 15. Mutation process } \\
\text { (for } \mathrm{k}=1: \mathrm{nm} \text { ) }\end{array}$ & $\begin{array}{l}\text { Select the mutation operator by a limited } \\
\text { predetermined random rate. }\end{array}$ \\
\hline Step 16. Generate the solution & The fitness for mutation solution. \\
\hline Step 17. Merge all solutions & $\begin{array}{l}\text { All solutions from current populations, Crossover } \\
\text { groups, and mutation populations. }\end{array}$ \\
\hline Step 18. Sort the best solution & $\begin{array}{l}\text { Select the best ones to form the next iteration } \\
\text { population. }\end{array}$ \\
\hline Step 19. Update velocities & Applying the velocity limits. \\
\hline Step 20. Modify the current positions & Using the updated velocities. \\
\hline Step 21. Generate the solution & Calculating the initial solutions. \\
\hline Step 22. Update pbest & The best position of the $i$ th particle. \\
\hline Step 23. Update gbest & The best position of the particle group. \\
\hline Step 24. Finalize the algorithm & For $\mathrm{k}=$ itermax. \\
\hline Step 25. Assign gbest and stop & The best solution and stop. \\
\hline
\end{tabular}

During this process, there were three crossover actions. The first is to generate the offspring/children from all populations to be half of the population (Group A). The second crossover process generates the children with the pbest solution to obtain the solution (Group B). The last crossover process contains the solution generated from all populations with its gbest (Group C). After performing crossover three times, the process continues to carry out the mutation and obtain the fitness solution. Finally, Groups A, B, and C and the mutation solution are sorted to obtain the best solutions for the next iteration. 


\section{Result}

\subsection{Initial Analysis}

For the initial evaluation, the locations of logistics centers along with the Korea Post amenities dataset from the IGIS were assigned to the study area [50]. The dataset includes 1999 nodes (centers and demands) from around the country, including place name, address, amenity type, and latitude-longitudinal locations. The dataset is presented on a layer of shape-file from IGIS and is processed using QGIS 3.20 Odense software [51].

In Figures 2 and 3, the red dots represent Korea Post Distribution (KPD) center locations while the blue dots represent the small retail Korea Post locations (demands). Using the OpenStreetMap layer, Figure 2 shows the detailed environment of the dot locations in the Seoul area, and Figure 3 shows all of the demands in South Korea. Because Seoul is the largest metropolitan city in South Korea, with more than 10 million people, its logistics demand is also extremely high. This is revealed by the number of blue dots on the Korea Post locations map in comparison to the population map [13], with clustered demands shown in Figure 3.

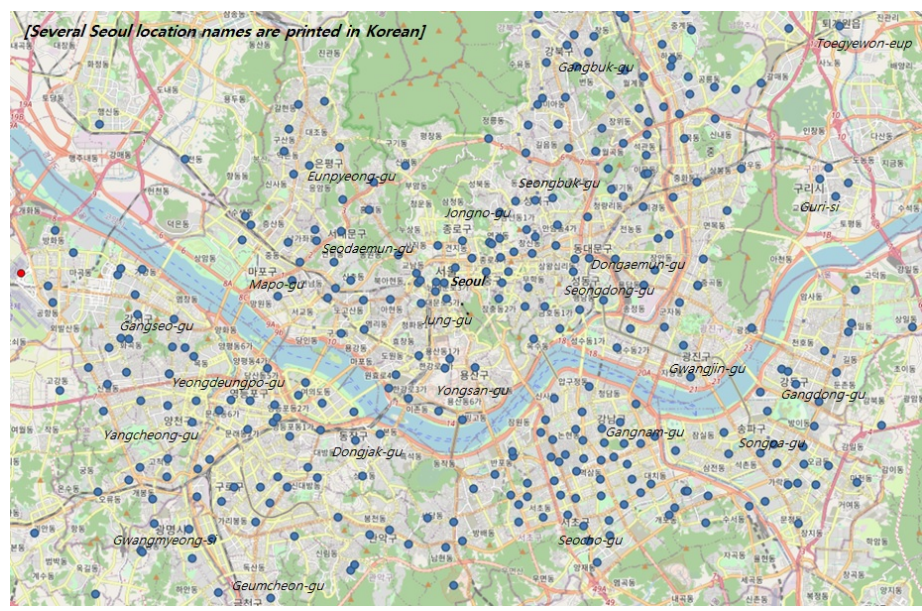

Figure 2. KPD centers and Korea Post facilities in Seoul.

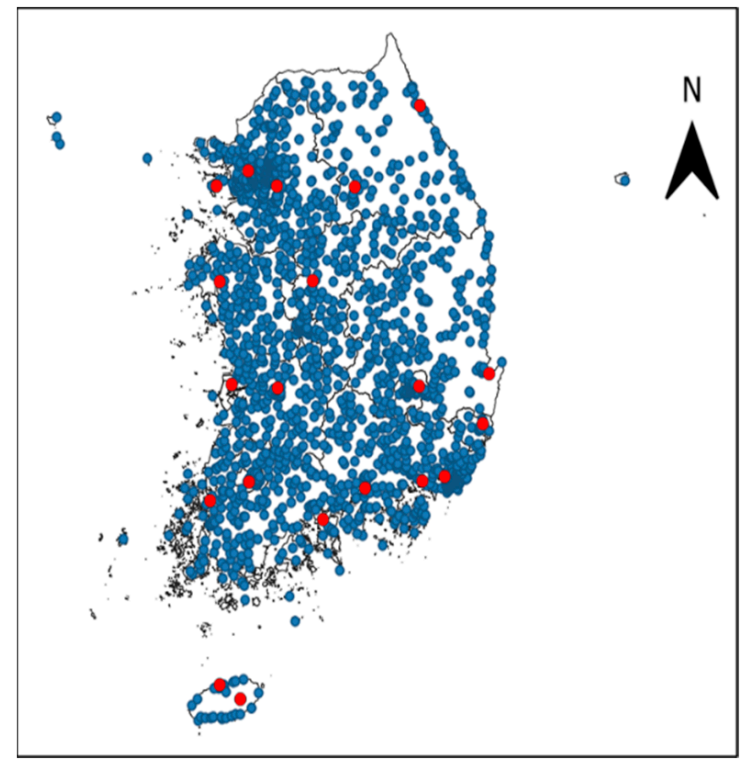

Figure 3. Mapped Korea Post and logistics center locations by QGIS 3.20 Odense software.

The dark red hexagons in Figure 4 represent the area with the highest number of demands (blue dots) within $10 \mathrm{~km}$. The number of demand dots is important for setting the network and spatial characteristics of logistics systems. 


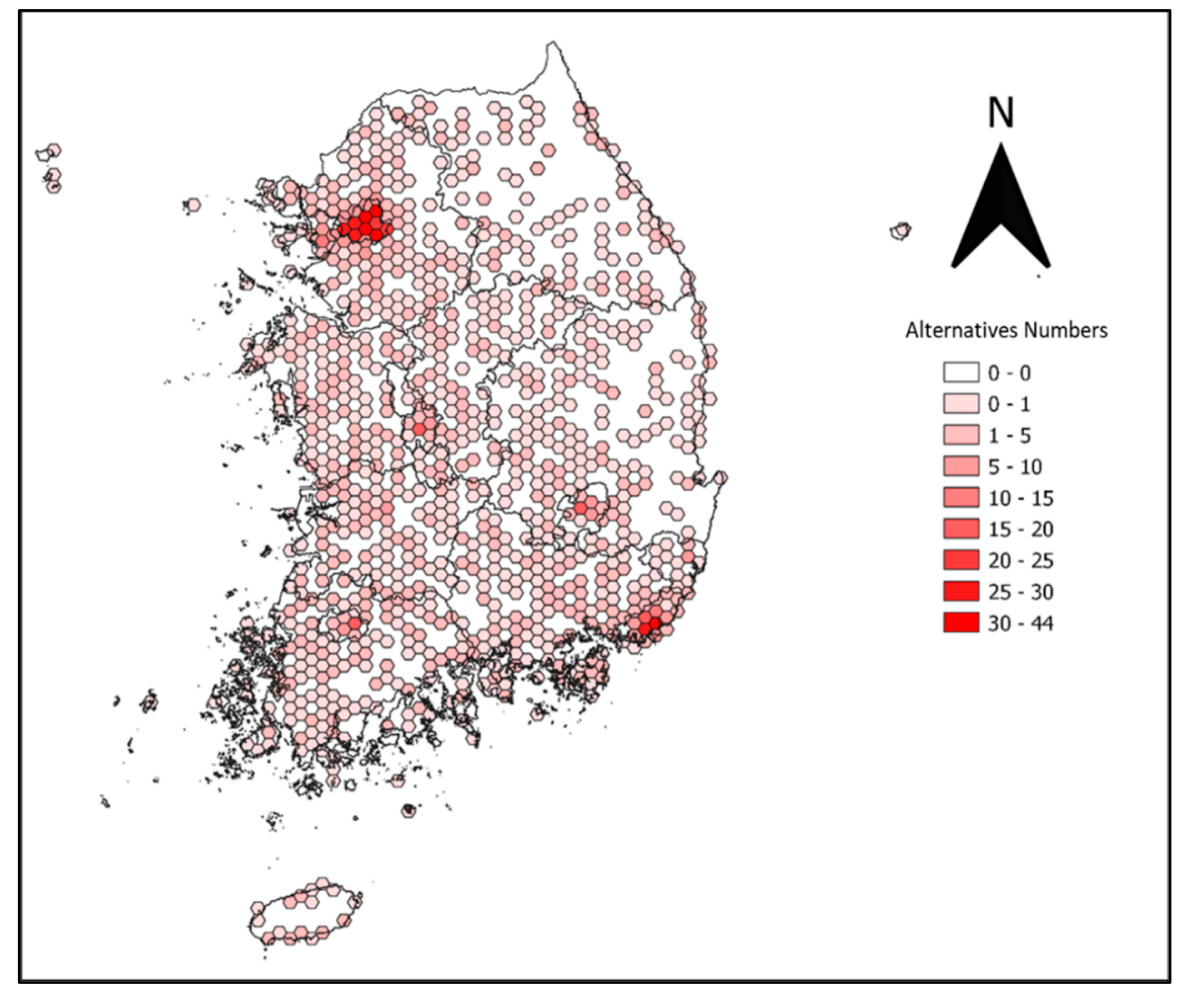

Figure 4. The clustering analysis of logistics demand.

\subsection{Spatial and Network Analysis for Location Section}

The model parameters for analyzing spatial analysis involve the distance matrix and logistics densities as priority values in choosing alternative locations. The distance matrix can be plotted using the GIS software distance matrix toolbox. The aim matrices calculate the exact length and clusters of the network used in the mathematical model.

In this research, we complete the clustering process by dividing the study area using the hot spot analysis plugin in GIS software with a hexagon-shaped grid, as shown in Figure 4 . Note that the hexagon can be replaced by other shapes. The coverage area for each hexagon was $10 \mathrm{~km}$ and the mapped points were counted within each hexagon region. After that, the number of facilities is counted to obtain the weighted points within the radius.

The facilities locations were analyzed using the Moran's I pattern analysis. The analysis contains three types of disparities: distributed, centralized, and clustered, as shown in Figure 5. Moran's I is calculated to ensure the logistics demands in South Korea are clustered (+1). By comparing the Figures 4 and 5, we can also obtain the general picture of logistics demands in South Korea that are clustered because the darker red hexagons are located in dense areas such as Seoul, Busan, and Daegu.

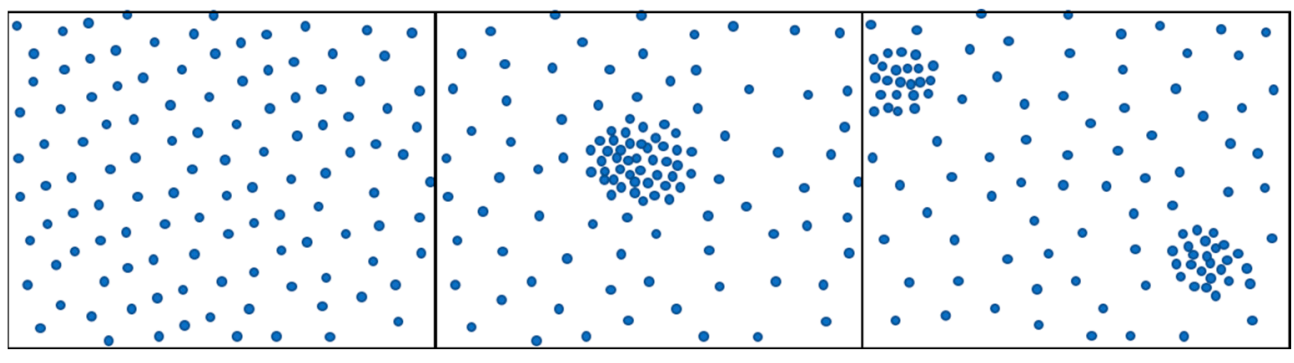

(a)

(b)

(c)

Figure 5. Type of disparity patterns (a) distributed, (b) centralized, and (c) clustered. 
The QGIS analysis revealed the disparities in logistics facilities around South Korea and confirmed that facilities are clustered in regions. Using the Getis-Ord toolbox, a weighted value is generated to provide the environmental difference between the highand low-demand areas as shown in Figure 6. The estimated weighted value is then used with the PSO-GA method for location analysis.

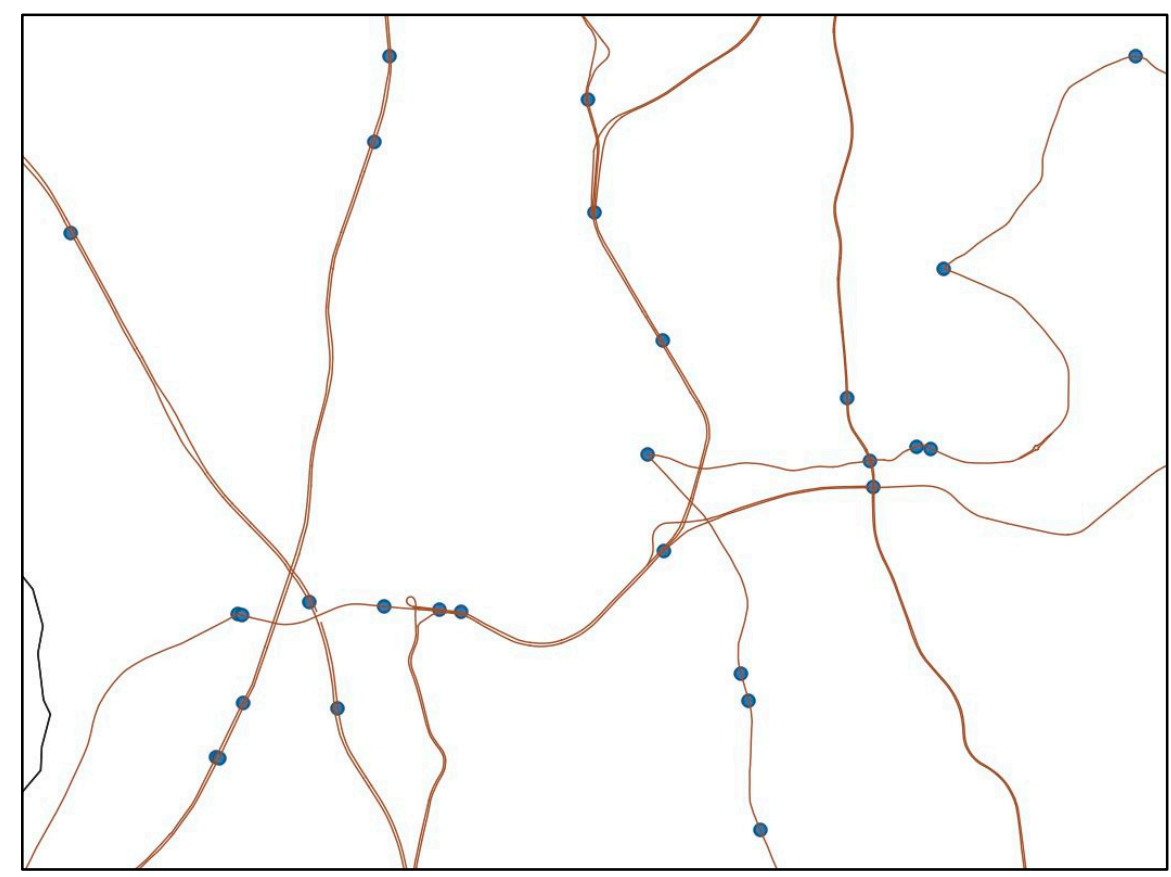

Figure 6. Disparity pattern in a region, Seoul using QGIS.

\subsection{Location Selection Using PSO-GA}

As explained in the previous section, location selection is a part of the logistics network problem in this study where " $p$ " centers on a network and " $m$ " nodes are considered for " $n$ " candidate facilities, with parameters being the minimum total weighted or unweighted distances of the related.

The logistics network analysis is calculated with the weighted and unweighted areas that were estimated in the previous section. The mathematical model is solved using the hybrid PSO-GA method, as provided in Section 3.2. Then, the results are compared with existing methods, such as the BPSO and PSO algorithms.

As mentioned previously, the size of a logistics network problem is variously based on the number of nodes and the number of related " $p$ " centers. This study considers five demand-number scenarios to test the model: 100, 150, 200, 350, and 600.

The demand numbers reflect the solution time differences and help us choose the proper network structure. As another performance distances travelled between demands are counted and reported. Table 6 lists the proposed parameter.

The three algorithms (the proposed hybrid PSO-GA, PSO, and BPSO) were calculated using (C MATLAB 2021Ra and run on an AMD Ryzen 3 4300U laptop with Radeon Graphics, 2.70 GHz with installed 16.00 GB RAM.

The proposed hybrid PSO-GA model uses an initial population size of 100 demands and the same number is applied for the BPSO and PSO algorithms, as provided in Table 4. The iteration number was set to 500 for PSO and 500 for GA in the PSO-GA process. For comparison, the iteration number set to 1000 for both BPSO and PSO. A small maximum velocity (Vmax) determines a value of 0 and promotes exploration as a pure random search. On the other hand, a large maximum velocity indicates limited exploration. In the latter case, the maximum velocity is set to 10 for maximum and the minimum velocity is set to -10 and is updated for each iteration. 
Table 6. PSO-GA parameters.

\begin{tabular}{cc}
\hline Parameters & Value \\
\hline Population size & 100 \\
PSO iter $\max$ & 500 \\
GA iter $\max$ & 500 \\
$w$ & 0.9 \\
$c_{1}, c_{2}$ & 2.0 \\
Velocity max & 10 \\
Velocity min & -10 \\
P $_{\text {cros }}$ & 0.8 \\
Extra range factor for crossover & 0.4 \\
P $_{\text {mut }}$ & 0.3 \\
Mutation rate & 0.1 \\
\hline
\end{tabular}

Choosing the inertia factor $(w)$ to slow particle velocities is a challenging step. If the value is less than 1 , convergence is prevented. If it is set to $-1<w<1, \mathrm{~V}_{i j}$ becomes zero over time. In this experiment, all of the algorithms used 0.9 for the inertia factor value. The learning factors $\left(c_{1}\right.$ and $\left.c_{2}\right)$ are both 2.0. There were no hardware or software differences in the processing of the solver operations.

\subsection{PSO-GA, BPSO and PSO Comparison}

The idea of the proposed algorithm is to improve the solution generation with each iteration by selection, mutation, and crossover operators. GA operators run until significant improvements are provided to the next generation. The best solutions are selected to achieve better solutions with each iteration. Therefore, the proposed PSO-GA is expected to provide superior logistics in less time.

The three algorithms PSO-GA, BPSO, and PSO are tested using two types of logistics network problems: weighted and unweighted. The weighted logistics network problem means that an area has a demand density value from GIS and, the unweighted logistics network problem means that an area has demand density with only area size. Both of the logistics network problems are applied for 100, 150, 200, 350, and 600 nodes with various numbers of medians. The results of solving for the solution time and total cost are given in Tables 7 and 8 respectively. To add complexity, the $p$-number is involved in the calculation for each network size using one to five instances.

Table 7 presents the solution times of each method, separated mainly based on their demand densities (weighted and unweighted). Moreover, the total cost values differ among these performances.

Consider the first case, for instance, when the network size is 100, and p is 1: the center that considers a weighted priority area calculates the total cost as $\$ 6,784,846$, while the unweighted one calculates the total cost as $\$ 6,185,364$. Calculations were performed repeatedly using the PSO-GA, BPSO, and PSO algorithms to validate the superior effectiveness of PSO-GA. Detailed performances and analyses are provided in the following section.

Table 7. Solution time (Unit: s) for weighted and unweighted center locations analysis.

\begin{tabular}{|c|c|c|c|c|c|c|c|}
\hline \multirow{2}{*}{$\begin{array}{l}\text { Network } \\
\text { Size }\end{array}$} & \multirow{2}{*}{$\begin{array}{c}\text { Center } \\
\text { Numbers }\end{array}$} & \multicolumn{3}{|c|}{ Weighted } & \multicolumn{3}{|c|}{ Unweighted } \\
\hline & & PSO-GA & BPSO & PSO & PSO-GA & BPSO & PSO \\
\hline \multirow[t]{5}{*}{100} & 1 & 17.8 & 19.51 & * 15.26 & 17.8 & 19.37 & * 16.6 \\
\hline & 2 & 26.88 & 28.92 & $* 23.6$ & *26.05 & 27.3 & $\overline{28.5}$ \\
\hline & 3 & 40.15 & 42.04 & $* 35.18$ & 34.44 & 35.42 & *33.94 \\
\hline & 4 & * 52.48 & 52.55 & $\overline{64.27}$ & 36.85 & 36.87 & $\overline{36.33}$ \\
\hline & 5 & $* 64.75$ & 64.75 & 74.17 & * 52.55 & * 52.55 & 55.59 \\
\hline
\end{tabular}


Table 7. Cont.

\begin{tabular}{|c|c|c|c|c|c|c|c|}
\hline \multirow{2}{*}{$\begin{array}{l}\text { Network } \\
\text { Size }\end{array}$} & \multirow{2}{*}{$\begin{array}{c}\text { Center } \\
\text { Numbers }\end{array}$} & \multicolumn{3}{|c|}{ Weighted } & \multicolumn{3}{|c|}{ Unweighted } \\
\hline & & PSO-GA & BPSO & PSO & PSO-GA & BPSO & PSO \\
\hline \multirow[t]{5}{*}{150} & 1 & $* 18.9$ & 21.71 & 25.13 & ${ }^{*} 18.6$ & 20.24 & 22.9 \\
\hline & 2 & $* 29.22$ & 31.81 & 43.96 & $\overline{28.22}$ & 28.72 & 35.81 \\
\hline & 3 & $* 37.62$ & 38.5 & 51.57 & *36.48 & 36.82 & 44.61 \\
\hline & 4 & $* 48.19$ & 48.45 & 68.77 & ${ }^{*} 44.08$ & 44.1 & 56.6 \\
\hline & 5 & ${ }^{* 60.92}$ & 60.93 & 108.49 & *58.24 & 58.25 & 88.27 \\
\hline \multirow[t]{5}{*}{200} & 1 & $* 19.6$ & 21.74 & 29.19 & $* 19.28$ & 20.48 & 29.99 \\
\hline & 2 & $\overline{28.98}$ & 31.34 & 55 & $* 26.9$ & 27.51 & 43.43 \\
\hline & 3 & $* 38.28$ & 38.79 & 67.59 & $* 32.94$ & 33.34 & 59.2 \\
\hline & 4 & ${ }^{*} 45.11$ & 45.33 & 87.86 & $* 44.77$ & 44.8 & 82.69 \\
\hline & 5 & * 62.99 & 63.00 & 126.19 & * 56.64 & $* 56.64$ & 105.79 \\
\hline \multirow[t]{5}{*}{350} & 1 & * 19.74 & 21.6 & 51.84 & $* 19.7$ & 21.41 & 51.74 \\
\hline & 2 & $\approx 29.61$ & 31.93 & 74.61 & $\overline{28.53}$ & 29.97 & 69.55 \\
\hline & 3 & *39.71 & 40.7 & 103.72 & $* 35.68$ & 35.75 & 95.28 \\
\hline & 4 & $* 50.72$ & 50.75 & 137.03 & $\overline{* 47.54}$ & 47.58 & 126.75 \\
\hline & 5 & *58.6 & 58.7 & 165.31 & $* 53.23$ & *53.23 & 142.4 \\
\hline \multirow[t]{5}{*}{600} & 1 & $* 24.8$ & 26.02 & 114.17 & $* 24.8$ & 25.95 & 114.43 \\
\hline & 2 & *34.82 & 35.61 & 154.72 & $* \overline{34.21}$ & 34.73 & 148.92 \\
\hline & 3 & * 45.01 & 45.28 & 188.21 & ${ }^{*} 43.97$ & 44.04 & 169.55 \\
\hline & 4 & *53.23 & 53.28 & 219.24 & $* 51.47$ & * 51.47 & 193.34 \\
\hline & 5 & *62.45 & 62.46 & 240.98 & $* 59.6$ & $* 59.6$ & 210.95 \\
\hline
\end{tabular}

*_: The fastest solution time between PSO-GA, BPSO, and PSO.

Table 8. Total cost for weighted and unweighted logistics network.

\begin{tabular}{|c|c|c|c|c|c|c|c|}
\hline \multirow{2}{*}{$\begin{array}{l}\text { Network } \\
\text { Size }\end{array}$} & \multirow{2}{*}{$\begin{array}{c}\text { Center } \\
\text { Numbers }\end{array}$} & \multicolumn{3}{|c|}{ Weighted } & \multicolumn{3}{|c|}{ Unweighted } \\
\hline & & PSO-GA & BPSO & PSO & PSO-GA & BPSO & PSO \\
\hline \multirow[t]{5}{*}{100} & 1 & $* 6,784,846$ & $7,353,068$ & $7,595,956$ & *6,185,364 & $6,377,843$ & $7,298,906$ \\
\hline & 2 & $* 4,877,929$ & $5,069,910$ & $5,153,367$ & ${ }^{*} 4,043,637$ & $4,072,727$ & $4,511,696$ \\
\hline & 3 & $* 3,393,564$ & $3,431,927$ & $3,533,054$ & *3,092,517 & $3,095,316$ & $3,275,586$ \\
\hline & 4 & $\overline{* 2,818,272}$ & $2,821,072$ & $2,932,206$ & *2,518,855 & $2,520,151$ & $2,543,161$ \\
\hline & 5 & ${ }^{*} 1,763,366$ & $1,763,368$ & $1,911,054$ & *1,171,394 & $1,171,394$ & $1,207,847$ \\
\hline \multirow[t]{5}{*}{150} & 1 & $* 9,042,946$ & $9,522,318$ & $10,321,644$ & $* 7,216,475$ & $7,377,402$ & $8,450,483$ \\
\hline & 2 & $\overline{* 7,644,466}$ & $7,823,251$ & $8,507,561$ & *6,939,100 & $7,003,634$ & $7,128,716$ \\
\hline & 3 & *5,876,466 & $5,934,848$ & $6,083,765$ & *5,736,261 & $5,746,503$ & $5,856,881$ \\
\hline & 4 & $* 5,080,874$ & $5,084,548$ & $5,203,901$ & $* 4,356,967$ & $4,358,221$ & $4,424,943$ \\
\hline & 5 & ${ }^{*} 3,080,313$ & $3,080,313$ & $3,243,602$ & *2,244,773 & $2,244,773$ & $2,294,832$ \\
\hline \multirow[t]{5}{*}{200} & 1 & * $15,455,923$ & $15,896,683$ & $16,815,694$ & * $12,499,662$ & $12,820,065$ & $14,220,570$ \\
\hline & 2 & * $12,216,102$ & $12,406,546$ & $12,686,042$ & $* 10,278,325$ & $10,361,579$ & $11,198,613$ \\
\hline & 3 & * $11,042,848$ & $11,133,431$ & $11,378,345$ & *6,035,975 & $6,042,011$ & $6,128,438$ \\
\hline & 4 & $* 9,160,556$ & $9,163,436$ & $9,312,371$ & $* 4,298,386$ & $4,298,898$ & $4,355,599$ \\
\hline & 5 & *7,617,892 & $7,617,895$ & $7,835,134$ & *3,726,939 & $3,726,939$ & $3,822,474$ \\
\hline \multirow[t]{5}{*}{350} & 1 & * $25,315,342$ & $26,120,812$ & $28,088,155$ & $* 19,474,204$ & $19,920,594$ & $21,923,949$ \\
\hline & 2 & *24,563,141 & $25,024,504$ & $26,237,113$ & * $16,656,473$ & $16,947,256$ & $18,272,058$ \\
\hline & 3 & *21,098,567 & $21,158,469$ & $21,207,856$ & * $11,942,141$ & $11,947,902$ & $12,279,723$ \\
\hline & 4 & *18,541,254 & $18,542,777$ & $18,903,948$ & $* 9,574,292$ & $9,574,534$ & $9,749,230$ \\
\hline & 5 & $\bar{*} 18,020,026$ & $18,020,026$ & $18,593,405$ & ${ }^{*} 7,127,513$ & $7,127,514$ & $7,290,892$ \\
\hline \multirow[t]{5}{*}{600} & 1 & * 38,488,771 & $39,248,242$ & $40,652,671$ & * 32,133,546 & $32,354,354$ & $34,253,238$ \\
\hline & 2 & *33,516,097 & $33,819,787$ & $34,586,945$ & *28,340,069 & $28,388,247$ & $28,817,317$ \\
\hline & 3 & $\overline{* 27,389,279}$ & $27,422,565$ & $27,601,760$ & *22,638,103 & $22,651,939$ & $22,713,302$ \\
\hline & 4 & *24,102,650 & $24,103,432$ & $24,322,685$ & *21,442,838 & $21,443,453$ & $21,501,632$ \\
\hline & 5 & * $22,455,322$ & $22,455,324$ & $22,898,416$ & *13,796,729 & $13,796,729$ & $13,891,560$ \\
\hline
\end{tabular}

*.: The lowest cost between PSO-GA, BPSO, and PSO. 


\section{Analysis and Discussion}

This study analyzes the performance of logistics centers by providing the hybrid PSOGA algorithm, and the result is compared with the existing techniques and approaches such as BPSO and PSO to evaluate the performance of proposed method.

Reviewing the Tables 7 and 8, the solution times and total costs of the three algorithms can be compared. Using the same parameters, the hybrid PSO-GA shows better performance in terms of solution time and total cost compared to the BPSO, and Tables 9 and 10 provide a comparison for the solution times and total costs respectively. The negative value indicates that the PSO-GA has better results than BPSO or PSO.

Table 9. The comparative solution time comparison for weighted and unweighted networks of each solver.

\begin{tabular}{|c|c|c|c|c|c|}
\hline \multirow{2}{*}{$\begin{array}{c}\text { Network } \\
\text { Size }\end{array}$} & \multirow{2}{*}{$\begin{array}{l}\text { Centers } \\
\text { Number }\end{array}$} & \multicolumn{2}{|c|}{ Weighted } & \multicolumn{2}{|c|}{ Unweighted } \\
\hline & & $\begin{array}{l}\text { BPSO vs. } \\
\text { PSO-GA }\end{array}$ & $\begin{array}{l}\text { PSO vs. } \\
\text { PSO-GA }\end{array}$ & $\begin{array}{l}\text { BPSO vs. } \\
\text { PSO-GA }\end{array}$ & $\begin{array}{l}\text { PSO vs. } \\
\text { PSO-GA }\end{array}$ \\
\hline \multirow[t]{5}{*}{100} & 1 & $-8.78 \%$ & $-18.34 \%$ & $-8.12 \%$ & $-8.61 \%$ \\
\hline & 2 & $-7.05 \%$ & $-12.70 \%$ & $-4.60 \%$ & $-5.47 \%$ \\
\hline & 3 & $-4.48 \%$ & $13.91 \%$ & $-2.78 \%$ & $1.42 \%$ \\
\hline & 4 & $-0.14 \%$ & $14.14 \%$ & $-0.05 \%$ & $1.46 \%$ \\
\hline & 5 & $0.00 \%$ & $16.67 \%$ & $0.00 \%$ & $7.25 \%$ \\
\hline \multirow[t]{5}{*}{150} & 1 & $-12.94 \%$ & $-43.84 \%$ & $-8.12 \%$ & $-34.02 \%$ \\
\hline & 2 & $-8.15 \%$ & $-33.53 \%$ & $-1.75 \%$ & $-22.12 \%$ \\
\hline & 3 & $-2.28 \%$ & $-29.93 \%$ & $-0.92 \%$ & $-21.19 \%$ \\
\hline & 4 & $-0.55 \%$ & $-27.05 \%$ & $-0.05 \%$ & $-18.77 \%$ \\
\hline & 5 & $0.00 \%$ & $-24.79 \%$ & $0.00 \%$ & $-18.23 \%$ \\
\hline \multirow[t]{5}{*}{200} & 1 & $-9.84 \%$ & $-50.08 \%$ & $-5.87 \%$ & $-46.46 \%$ \\
\hline & 2 & $-7.52 \%$ & $-48.65 \%$ & $-2.21 \%$ & $-45.87 \%$ \\
\hline & 3 & $-1.32 \%$ & $-47.31 \%$ & $-1.18 \%$ & $-44.35 \%$ \\
\hline & 4 & $-0.48 \%$ & $-43.37 \%$ & $-0.08 \%$ & $-38.05 \%$ \\
\hline & 5 & $0.00 \%$ & $-2.84 \%$ & $0.00 \%$ & $-35.71 \%$ \\
\hline \multirow[t]{5}{*}{350} & 1 & $-8.59 \%$ & $-64.55 \%$ & $-7.97 \%$ & $-62.62 \%$ \\
\hline & 2 & $-7.25 \%$ & $-62.99 \%$ & $-4.82 \%$ & $-62.55 \%$ \\
\hline & 3 & $-2.43 \%$ & $-61.92 \%$ & $-0.18 \%$ & $-62.49 \%$ \\
\hline & 4 & $-0.07 \%$ & $-61.71 \%$ & $-0.07 \%$ & $-61.92 \%$ \\
\hline & 5 & $0.00 \%$ & $-60.31 \%$ & $0.00 \%$ & $-58.98 \%$ \\
\hline \multirow[t]{5}{*}{600} & 1 & $-4.70 \%$ & $-78.28 \%$ & $-4.42 \%$ & $-78.33 \%$ \\
\hline & 2 & $-2.23 \%$ & $-77.50 \%$ & $-1.49 \%$ & $-77.03 \%$ \\
\hline & 3 & $-0.59 \%$ & $-76.08 \%$ & $-0.15 \%$ & $-74.07 \%$ \\
\hline & 4 & $-0.10 \%$ & $-75.72 \%$ & $0.00 \%$ & $-73.38 \%$ \\
\hline & 5 & $0.00 \%$ & $-74.09 \%$ & $0.00 \%$ & $-71.75 \%$ \\
\hline
\end{tabular}

Compared to BPSO, PSO-GA offers an $80 \%$ better solution-time performance among the repetition. On the same hand, PSO-GA provides approximately $88 \%$ better solutiontime performance compared to the PSO algorithm. At a higher p-number, based on the presented results, the proposed PSO-GA shows very small differences, at some points almost $0 \%$.

The proposed PSO-GA also provides better performance compared to BPSO in weighted logistics networks in both solution time and total cost results. The PSO-GA hybrid is $80 \%$ more effective than BPSO in solving the cost calculation. However, at a higher level of complexity, the PSO-GA and BPSO provide the same quality of performance with almost zero difference between the two solvers. 
Table 10. The comparative total cost comparison for unweighted and weighted logistics network of each solver compared to PSO-GA solver.

\begin{tabular}{|c|c|c|c|c|c|}
\hline \multirow[b]{2}{*}{$\begin{array}{c}\text { Network } \\
\text { Size }\end{array}$} & \multirow[b]{2}{*}{$\begin{array}{c}\text { Center } \\
\text { Numbers }\end{array}$} & \multicolumn{2}{|c|}{ Weighted } & \multicolumn{2}{|c|}{ Unweighted } \\
\hline & & $\begin{array}{l}\text { BPSO vs. } \\
\text { PSO-GA }\end{array}$ & $\begin{array}{l}\text { PSO vs. } \\
\text { PSO-GA }\end{array}$ & $\begin{array}{l}\text { BPSO vs. } \\
\text { PSO-GA }\end{array}$ & $\begin{array}{l}\text { PSO vs. } \\
\text { PSO-GA }\end{array}$ \\
\hline \multirow[t]{5}{*}{100} & 1 & $-7.73 \%$ & $-10.68 \%$ & $-3.02 \%$ & $-15.26 \%$ \\
\hline & 2 & $-3.79 \%$ & $-7.73 \%$ & $-0.71 \%$ & $-10.37 \%$ \\
\hline & 3 & $-1.12 \%$ & $-5.34 \%$ & $-0.09 \%$ & $-5.59 \%$ \\
\hline & 4 & $-0.10 \%$ & $-3.95 \%$ & $-0.05 \%$ & $-3.02 \%$ \\
\hline & 5 & $0.00 \%$ & $-3.89 \%$ & $0.00 \%$ & $-0.96 \%$ \\
\hline \multirow[t]{5}{*}{150} & 1 & $-5.03 \%$ & $-12.39 \%$ & $-2.18 \%$ & $-14.60 \%$ \\
\hline & 2 & $-2.29 \%$ & $-10.15 \%$ & $-0.92 \%$ & $-2.66 \%$ \\
\hline & 3 & $-0.98 \%$ & $-5.03 \%$ & $-0.18 \%$ & $-2.18 \%$ \\
\hline & 4 & $-0.07 \%$ & $-3.41 \%$ & $-0.03 \%$ & $-2.06 \%$ \\
\hline & 5 & $0.00 \%$ & $-2.36 \%$ & $0.00 \%$ & $-1.54 \%$ \\
\hline \multirow[t]{5}{*}{200} & 1 & $-2.77 \%$ & $-8.09 \%$ & $-2.50 \%$ & $-12.10 \%$ \\
\hline & 2 & $-1.54 \%$ & $-3.70 \%$ & $-0.80 \%$ & $-8.22 \%$ \\
\hline & 3 & $-0.81 \%$ & $-2.95 \%$ & $-0.10 \%$ & $-2.50 \%$ \\
\hline & 4 & $-0.03 \%$ & $-2.77 \%$ & $-0.01 \%$ & $-1.51 \%$ \\
\hline & 5 & $0.00 \%$ & $-1.63 \%$ & $0.00 \%$ & $-1.31 \%$ \\
\hline \multirow[t]{5}{*}{350} & 1 & $-3.08 \%$ & $-9.87 \%$ & $-2.24 \%$ & $-11.17 \%$ \\
\hline & 2 & $-1.84 \%$ & $-6.38 \%$ & $-1.72 \%$ & $-8.84 \%$ \\
\hline & 3 & $-0.28 \%$ & $-3.08 \%$ & $-0.05 \%$ & $-2.75 \%$ \\
\hline & 4 & $-0.01 \%$ & $-1.92 \%$ & $0.00 \%$ & $-2.24 \%$ \\
\hline & 5 & $0.00 \%$ & $-0.52 \%$ & $0.00 \%$ & $-1.79 \%$ \\
\hline \multirow[t]{5}{*}{600} & 1 & $-1.94 \%$ & $-5.32 \%$ & $-0.68 \%$ & $-6.19 \%$ \\
\hline & 2 & $-0.90 \%$ & $-3.10 \%$ & $-0.17 \%$ & $-1.66 \%$ \\
\hline & 3 & $-0.12 \%$ & $-1.94 \%$ & $-0.06 \%$ & $-0.68 \%$ \\
\hline & 4 & $0.00 \%$ & $-0.90 \%$ & $0.00 \%$ & $-0.33 \%$ \\
\hline & 5 & $0.00 \%$ & $-0.77 \%$ & $0.00 \%$ & $-0.27 \%$ \\
\hline
\end{tabular}

In PSO-GA and BPSO comparisons, PSO-GA provides a slightly faster solution time for the weighted logistics network compared to the unweighted one. On the other hand, PSO-GA provides $88 \%$ faster solution during repetition when handling unweighted $\mathrm{p}$ median problems compare to the original PSO. A noticeable characteristic is that the larger the network size of a problems, the longer PSO needs to solve it. On the other hand, PSO solves higher-complexity problems faster.

PSO-GA solved the problems within a significantly shorter period of time compared to PSO. The proposed algorithm sorts the offspring solution and takes only the best to be reviewed as a new population for the next iteration; PSO-GA searches for the optimum solution among the best solutions, so it saves time providing the final solution. The best solutions of PSO-GA result not only from crossing the population over its pbest and gbest, but also through crossover and population mutation.

Therefore, obtaining the best solution is achieved faster than by reviewing ordinary populations. Figure 7 shows the effectiveness of the proposed model.

Despite solving the weighted logistics network $78 \%$ faster than the unweighted network, the total cost calculation demonstrates that PSO-GA provides a slightly better management cost for unweighted logistics network problems. In particular, PSO-GA offers $4.71 \%$ better average cost-saving performance for weighted problems, and $4.79 \%$ for unweighted. 


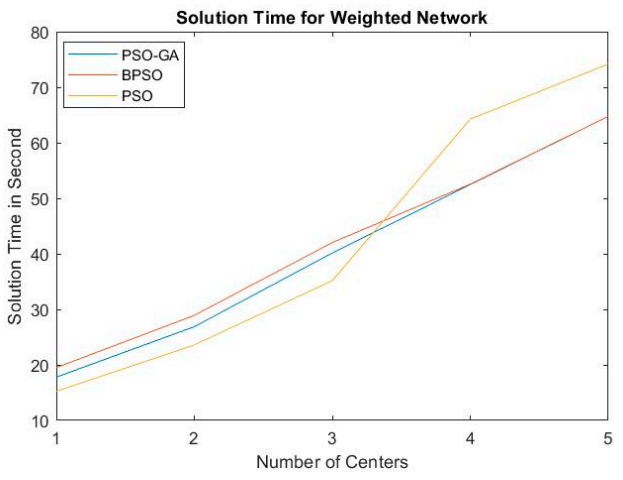

(a)

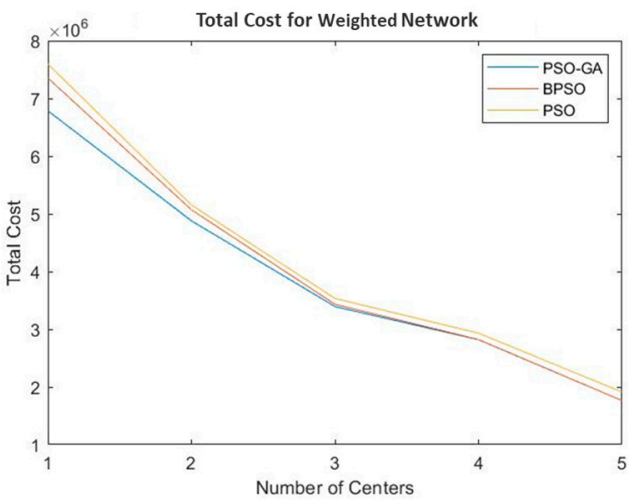

(c)

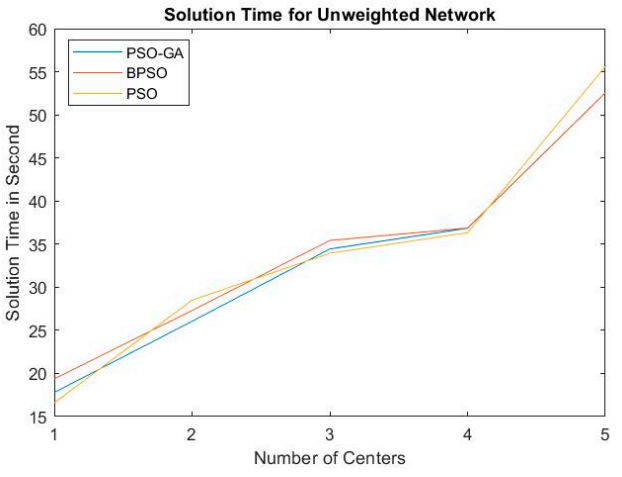

(b)

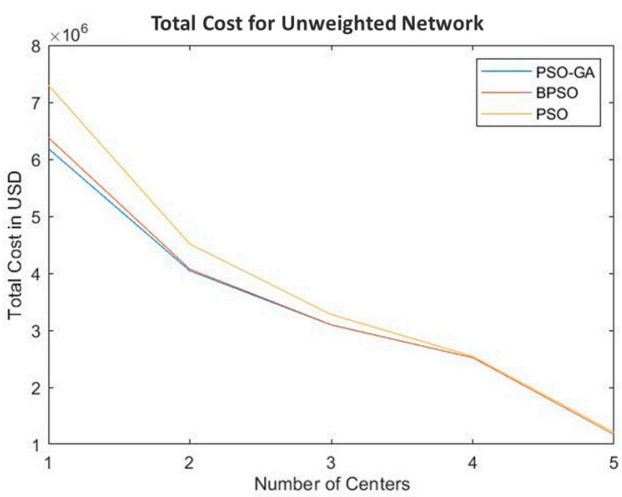

(d)

Figure 7. PSO-GA, BPSO, and PSO comparison in Solution Time and Total Cost. (a) Solution Time for Weighted Network, (b) Solution Time for Unweighted Network, (c) Total Cost for Weighted Network, and (d) Total Cost for Unweighted Network.

Despite the good result, this study has limitation in terms of distribution scale. Since logistics is not restricted to the distribution between one city and another but also includes the distribution between countries, this should be considered to obtain a broad perspective in distribution processes globally. Having a positive result compared to existing studies, the proposed model is expected to be improved in the future to signify the differences and help researchers in reviewing the performance of logistics centers.

\section{Conclusions}

The selection of a logistic center requires a solution that can connect transportation nodes and minimize the transportation cost between those nodes. This study proposes the integration of a geographic information system with a hybrid metaheuristic algorithm. The first step uses a GIS-based analysis, which provides spatial and network analysis using hotspot analysis. The calculation uses Moran's index considering $z$-score, $p$-value, and Getis-Ord statistics. These values are important because they provide network priorities. These priorities are determined using demand density values.

The next step is an analyzing process using the proposed PSO-GA method. The parameters are driven from the previous GIS analysis. The proposed method provides shorter solution times for both weighted and unweighted logistics networks compared to other existing metaheuristics, such as BPSO and PSO. However, in solving larger and higher levels of network complexity, the difference in solution times between PSO-GA and BPSO is almost zero. The total cost difference between PSO-GA and BPSO is also small, but the proposed PSO-GA does provide a comparatively lower total cost. PSO-GA also demonstrates better performance in both weighted and unweighted logistics network 
solutions compared to PSO alone. Overall, PSO-GA is proven to be an efficient method for logistics center location analysis compared to the existing optimization models.

In this study, Seoul, South Korea, was a test site for the analysis. In future studies, much broader regions for logistic selection should be considered. Modification of the proposed method is expected.

Author Contributions: Maryam Khairunissa conceptualized the method and developed the methodologies; Maryam Khairunissa implemented the method; Hyunsoo Lee supported the data and validated the method and the implementation; Hyunsoo Lee supervised the overall research processes and wrote the manuscript; Hyunsoo Lee reviewed and edited the manuscript. All authors have read and agreed to the published version of the manuscript.

Funding: This research was supported by The Basic Science Research Program through the National Research Foundation of Korea (NRF) funded by the Ministry of Education, S. Korea (grant number: NRF-2021R1A2C1008647).

Institutional Review Board Statement: Not applicable.

Informed Consent Statement: Not applicable.

Data Availability Statement: The data presented in this study are available from the author upon reasonable request.

Conflicts of Interest: The authors declare no conflict of interest.

\section{References}

1. Kabak, Ö.; Ekici, Ş.Ö.; Ülengin, F. Analyzing two-way interaction between the competitiveness and logistics performance of countries. Transp. Policy 2020, 98, 238-246. [CrossRef]

2. Wiederer, C.K.; Arvis, J.; Ojala, L.M.; Kiiski, T.M.M. The World Bank's Logistics Performance Index. In International Encyclopedia of Transportation; Vickerman, R., Ed.; Elsevier: Amsterdam, The Netherlands, 2021; pp. 94-101.

3. Kaynak, R.; Koçoğlu, İ.; Akgün, A.E. The Role of Reverse Logistics in the Concept of Logistics Centers. Procedia-Soc. Behav. Sci. 2019, 109, 438-442. [CrossRef]

4. Uyanık, C.; Tuzkaya, G.; Oguztimur, S. A Literature Survey on Logistics Centers' Location Selection Problem. Signa J. Eng. Nat. Sci. 2018, 36, 141-160.

5. Kechagias, E.P.; Gayialis, S.P.; Konstantakopoulos, G.D.; Papadopoulos, G.A. An application of an urban freight transportation system for reduced environmental emissions. Systems 2020, 8, 49. [CrossRef]

6. Mohtashami, Z.; Aghsami, A.; Jolai, F. A green closed loop supply chain design using queuing system for reducing environmental impact and energy consumption. J. Clean. Prod. 2020, 242, 118452. [CrossRef]

7. Konstantakopoulos, G.D.; Gayialis, S.P.; Kechagias, E.P.; Papadopoulos, G.A.; Tatsiopoulos, I.P. A Multiobjective Large Neighborhood Search Metaheuristic for the Vehicle Routing Problem with Time Windows. Algorithms 2020, 13, 243. [CrossRef]

8. Khalid, B.; Urbański, M.; Kowalska-Sudyka, M.; Wysłocka, E.; Piontek, B. Evaluating consumers' adoption of renewable energy. Energies 2021, 14, 7138. [CrossRef]

9. Europlatforms. Available online: http:/ / www.europlatforms.eu/?page_id=150 (accessed on 15 July 2021).

10. Touboulic, A.; McCarthy, L.; Matthews, L. Re-imagining supply chain challenges through critical engaged research. J. Supply Chain Manag. 2020, 56, 36-51. [CrossRef]

11. Vieira, B.O.; Guarnieri, P.; Nofal, R.; Nofal, B. Multi-Criteria Methods Applied in the Studies of Barriers Identified in the Implementation of Reverse Logistics of E-Waste: A Research Agenda. Logistics 2020, 4, 11. [CrossRef]

12. Stević, Ž;; Brković, N. A Novel Integrated FUCOM-MARCOS Model for Evaluation of Human Resources in a Transport Company. Logistics 2020, 4, 4. [CrossRef]

13. World Population Review. Available online: https://worldpopulationreview.com/countries/south-korea-population (accessed on 15 July 2021).

14. Rodrigue, J.; Comtois, C.; Slack, B. The Geography of Transport Systems, 5th ed.; Routledge: London, UK, 2013 ; pp. 72-76.

15. Rao, C.; Goh, M.; Zhao, Y.; Zheng, J. Location selection of city logistics centers under sustainability. Transp. Res. Part D Transp. Environ. 2015, 36, 29-44. [CrossRef]

16. Bell, M.G.H. Chapter 20-City logistics and the urban environment. In Urban Form and Accessibility; Mulley, C., Nelson, J.D., Eds.; Elsevier: Amsterdam, The Netherlands, 2021; pp. 359-378.

17. Kunaka, C. Logistics in the Developing World. In International Encyclopedia of Transportation; Vickerman, R., Ed.; Elsevier: Amsterdam, The Netherlands, 2021; pp. 150-156.

18. Pohit, S.; Gupta, D.B.; Pratap, D.; Malik, S. Survey of Literature on Measuring Logistics Cost: A Developing Country's Perspective. J. Asian Econ. Integr. 2019, 1, 260-282. [CrossRef] 
19. Barykin, S.Y.; Kapustina, I.V.; Sergeev, S.M.; Kalinina, O.V.; Vilken, V.V.; Putikhin, Y.Y.; Volkova, L.V. Developing the physical distribution digital twin model within the trade network. Acad. Strateg. Manag. J. 2021, 20, 1-24.

20. Aljohani, K.; Thompson, R.G. Impacts of logistics sprawl on the urban environment and logistics: Taxonomy and review of literature. J. Transp. Geogr. 2016, 57, 255-263. [CrossRef]

21. Oh, E.; Lee, H. Development of Convolution-based Multi-directional and Parallel Ant Colony Algorithm considering Network with Dynamic Topology Changes. Appl. Sci. 2019, 9, 3646. [CrossRef]

22. Lee, H. Effective Dynamic Control Strategy of a Key Supplier with Multiple Downstream Manufacturers using Industrial Internet of Things and Cloud System. Processes 2019, 7, 172. [CrossRef]

23. Oh, E.; Lee, H. Effective Routing Generation Framework using Multi-directional and Parallel Ant Colony Optimization. J. Korean Inst. Intell. Syst. 2018, 28, 523-530.

24. Shahparvari, S.; Nasirian, A.; Mohammadi, A.; Noori, S.; Chhetri, P. A GIS-LP integrated approach for the logistics hub location problem. Comput. Ind. Eng. 2020, 146, 106488. [CrossRef]

25. Hagino, Y.; Endo, K. A potential analysis of distribution facilities locations using discrete choice modeling in Tokyo Metropolitan Region. Infrastruct. Plan. Rev. 2007, 24, 103-110. [CrossRef]

26. Hua, X.; Hu, X.; Yuan, W. Research optimization on logistics distribution center location based on adaptive particle swarm algorithm. Optik 2016, 127, 8443-8450. [CrossRef]

27. Shimizu, Y.; Miura, T. Effect of Topology on Parallel Computing for Optimizing Large Scale Logistics through Binary PSO. In Computer Aided Chemical Engineering; Bogle, I.D.L., Fairweather, M., Eds.; Elsevier: Amsterdam, The Netherlands, 2012; Volume 30, pp. 1247-1251.

28. Wang, Y.; Ma, X.; Xu, M.; Liu, Y.; Wang, Y. Two-echelon logistics distribution region partitioning problem based on a hybrid particle swarm optimization-Genetic algorithm. Expert Syst. Appl. 2015, 42, 5019-5031. [CrossRef]

29. Çakmak, E.; Önden, İ.; Acar, A.Z.; Eldemir, F. Analyzing the location of city logistics centers in Istanbul by integrating Geographic Information Systems with Binary Particle Swarm Optimization algorithm. Case Stud. Transp. Policy 2021, 9, 59-67. [CrossRef]

30. Shimizu, Y.; Miura, T. A Parallel Computing Scheme for Large-Scale Logistics Network Optimization Enhanced by Discrete Hybrid PSO. In Computer Aided Chemical Engineering; Elsevier: Amsterdam, The Netherlands, 2009; pp. 2031-2036.

31. Hiassat, A.; Diabat, A.; Rahwan, I. A genetic algorithm approach for location-inventory-routing problem with perishable products. J. Manuf. Syst. 2017, 42, 93-103. [CrossRef]

32. Gajpal, Y.; Abad, P. An ant colony system (ACS) for vehicle routing problem with simultaneous delivery and pickup. Comput. Oper. Res. 2009, 36, 3215-3223. [CrossRef]

33. Shoja, A.; Molla-Alizadeh-Zavardehi, S.; Niroomand, S. Hybrid adaptive simplified human learning optimization algorithms for supply chain network design problem with possibility of direct shipment. Appl. Soft Comput. 2020, 96, 106594. [CrossRef]

34. Kachitvichyanukul, V.; Sombuntham, P.; Kunnapapdeelert, S. Two solution representations for solving multi-depot vehicle routing problem with multiple pickup and delivery requests via PSO. Comput. Ind. Eng. 2015, 89, 125-136. [CrossRef]

35. Marinaki, M.; Marinakis, Y. A Glowworm Swarm Optimization algorithm for the Vehicle Routing Problem with Stochastic Demands. Expert Syst. Appl. 2016, 46, 145-163. [CrossRef]

36. Albayrak, M.; Allahverdi, N. Development a new mutation operator to solve the Traveling Salesman Problem by aid of Genetic Algorithms. Expert Syst. Appl. 2011, 38, 1313-1320. [CrossRef]

37. Sakai, T.; Kawamura, K.; Hyodo, T. Logistics facilities for intra and inter-regional shipping: Spatial distributions, location choice factors, and externality. J. Transp. Geogr. 2020, 86, 102783. [CrossRef]

38. Van den Heuvel, F.P.; de Langen, P.W.; van Donselaar, K.H.; Fransoo, J.C. Spatial concentration and location dynamics in logistics: The case of a Dutch province. J. Transp. Geogr. 2013, 28, 39-48. [CrossRef]

39. Baban, S.M.J.; Parry, T. Developing and applying a GIS-assisted approach to locating wind farms in the UK. Renew. Energy 2001, 24, 59-71. [CrossRef]

40. Chen, Y.; Huang, Z.; Ai, H.; Guo, X.; Luo, F. The Impact of GIS/GPS Network Information Systems on the Logistics Distribution Cost of Tobacco Enterprises. Transp. Res. Part E Logist. Transp. Rev. 2021, 149, 102299. [CrossRef]

41. Klose, A.; Drexl, A. Facility location models for distribution system design. Eur. J. Oper. Res. 2005, 162, 4-29. [CrossRef]

42. Yazdani, M.; Chatterjee, P.; Pamucar, D.; Chakraborty, S. Development of an integrated decision-making model for location selection of logistics centers in the Spanish autonomous communities. Expert Syst. Appl. 2020, 148, 113208. [CrossRef]

43. Ogato, G.S.; Bantider, A.; Abebe, K.; Geneletti, D. Geographic information system (GIS)-Based multicriteria analysis of flooding hazard and risk in Ambo Town and its watershed, West shoa zone, oromia regional State, Ethiopia. J. Hydrol. Reg. Stud. 2020, 27, 100659. [CrossRef]

44. Ziakopoulos, A. Spatial analysis of harsh driving behavior events in urban networks using high-resolution smartphone and geometric data. Accid. Anal. Prev. 2021, 157, 106189. [CrossRef]

45. Everett, B.I.; Fennessy, S.T.; van den Heever, N. Using hotspot analysis to track changes in the crustacean fishery off KwaZuluNatal, South Africa. Reg. Stud. Mar. Sci. 2021, 41, 101553. [CrossRef]

46. Kumari, M.; Sarma, K.; Sharma, R. Using Moran's I and GIS to study the spatial pattern of land surface temperature in relation to land use/cover around a thermal power plant in Singrauli district, Madhya Pradesh, India. Remote Sens. Appl. Soc. Environ. 2019, 15, 100239. [CrossRef] 
47. ArcGIS Pro-What Is a z-Score? What Is $p$-Value? Available online: https://pro.arcgis.com/en/pro-app/latest/tool-reference/ spatial-statistics / what-is-a-z-score-what-is-a-p-value.htm (accessed on 21 July 2021).

48. Gwalani, H.; Tiwari, C.; Mikler, A.R. Evaluation of heuristics for the p-median problem: Scale and spatial demand distribution. Comput. Environ. Urban Syst. 2021, 88, 101656. [CrossRef]

49. Yang, X.S. Nature-Inspired Optimization Algorithms, 2nd ed.; Section 6; Academic Press: London, UK, 2021.

50. Logistics Centers and Korea Post Points. Available online: https://map.igismap.com/ (accessed on 1 July 2021).

51. QGIS Application. Available online: https://www.qgis.org/en/site/ (accessed on 1 July 2021). 